\title{
EL TEMOR AL «REINADO DEL POPULACHO». EL CONCEPTO DE DEMOCRACIA DURANTE LA INDEPENDENCIA CHILENA $^{1}$
}

\author{
The writing in the outside of the language in Enrique Lihn and Germán Marin
}

\author{
Gabriel Cid Rodríguez*
}

\begin{abstract}
RESUMEN
El trabajo analiza las polémicas en torno a los usos del concepto de democracia durante el proceso de Independencia chilena, entre 1808 y 1833. Mediante una aproximación desde la historia conceptual se examinan los debates y diversas valoraciones de la democracia en sus diferentes articulaciones semánticas con otros conceptos (como pueblo, libertad e igualdad) así como con una serie de problemas propios de la constitución de un régimen de modernidad política, en especial, la delimitación de los marcos de participación ciudadana.
\end{abstract}

Palabras clave: democracia, historia conceptual, independencia, revolución, representación.

\begin{abstract}
The paper analyzes the controversies about the uses of the concept of democracy during the Chilean Independence (1808-1833). Through an approach from the conceptual history, the article analyzes the discussions and various assessments of democracy in

\footnotetext{
${ }^{1}$ Este trabajo forma parte del proyecto Fondecyt de Iniciación No 11160298, titulado: "El espectro del pueblo: la conceptualización de la democracia en Chile, 1841-1887".

* Programa de Historia de las Ideas Políticas en Chile, Universidad Diego Portales. Santiago, Chile. Correo electrónico: gabriel.cid@udp.cl
}

Artículo recibido el 20 de diciembre de 2016. Aceptado el 17 de marzo de 2017.
\end{abstract}


different semantic links with other concepts (as a people, freedom and equality), and with a series of problems in the establishment of a regime of political modernity, especially the delimitation of the frameworks for citizen participation.

Keywords: Democracy, conceptual history, independence, revolution, representation.

"Valiéndose a cada rato de las voces pueblo, soberanía del pueblo, los demócratas chilenos marchan a paso redoblado, sin saber a dónde van, pero sabiendo lo que quieren [...] ¿A dónde iríamos a dar si las máximas de ese partido fueran adoptadas? Directamente a una revolución inevitable, al reinado del populacho"2.

\section{INTRODUCCIÓN: HISTORIA CONCEPTUAL Y DEMOCRACIA}

En el mundo contemporáneo pocos conceptos políticos resultan tan evocadores como el de democracia. Ese "encanto ecuménico" -John Dunn dixit- ${ }^{3}$ del que se revistió el concepto desde la segunda mitad del siglo XX, y la consiguiente naturalización de la condición democrática en el mundo occidental, tiene el riesgo de arrojar un velo sobre su compleja y oscilante trayectoria histórica. En efecto, según lo muestra un detenido análisis conceptual, la supuesta naturalidad de las adhesiones al imperativo democrático es más bien una ilusión retrospectiva que una constatación propiamente histórica.

Como ha argumentado Rusell L. Hanson, hasta mediados del siglo XIX, la democracia fue considerada como una forma peligrosa e inestable de gobierno. Solo tras la Segunda Guerra Mundial se produjo la "popularización de la democracia”, y esta se tornó en un valor deseable y universal. No obstante, este nuevo estatus tuvo un efecto paradojal, pues la democracia se devaluó conceptualmente. Su pretensión omnicomprensiva, su constante uso por diversos sectores y para diversos intereses terminó por transformarla en una "palabra hurra", por la pérdida del contenido clasista que había estado en el núcleo de su carga semántica ${ }^{4}$. Por cierto, esta relativa vacuidad en su significado ha tenido repercusiones en términos heurísticos. En algunos casos, se prefiere invocar neologismos que den cuenta de una mayor precisión interpretativa (como el de poliarquia, de Robert A. Dahl) ${ }^{5}$; o,

\footnotetext{
${ }^{2}$ El Verdadero Liberal, 04 de enero de 1827.

${ }^{3}$ Dunn, John. Libertad para el pueblo. Historia de la democracia. México D.F.: Fondo de Cultura Económica, (2014): 29.

${ }^{4}$ Hanson, Russell L. "Democracy". Political Innovation and Conceptual Change. In Terence Ball, James Farr y Russell L. Hanson (eds.). Cambridge: Cambridge University Press (1989): 68-89.

${ }^{5}$ Dahl, Robert A. A Preface to Democratic Theory. Chicago: The University of Chicago Press, 1956.
} 
de forma más frecuente, se opta por una creciente adjetivación para confrontar el decrecimiento explicativo de la democracia a secas ${ }^{6}$.

Esta constatación nos obliga a aproximarnos hacia el pasado con una mirada más atenta al contenido polémico de los discursos históricos y más cercano a sus horizontes de posibilidad, una prevención que se advierte especialmente necesaria respecto a la democracia. En efecto, al dar por establecida una norma abstracta de lo que "debería ser" la democracia, y desde allí juzgar la experiencia histórica, resulta claro que el balance no es positivo, particularmente en el caso latinoamericano ${ }^{7}$. Sin embargo, habría que interrogarse si durante el período aquí examinado, la primera mitad del siglo XIX, en alguna parte del mundo occidental existió ese supuesto canon democrático de aceptación transversal.

Algunos datos proporcionados por la historia conceptual son decidores respecto lo simplista de esta aproximación, pues durante el marco temporal aquí estudiado la democracia fue un concepto que no despertó muchas adhesiones. Como concluyó R. R. Palmer, durante la era de las revoluciones la democracia fue una palabra peligrosa, que aludía a una forma de gobierno obsoleta en estado puro - de acuerdo a la tradición clásica- que solo podía morigerarse al mezclarse con otras formas de gobierno. La experiencia jacobina durante la Revolución francesa solo confirmó el tradicional descrédito hacia la democracia ${ }^{8}$. En EE.UU., la trayectoria es similar, y solo en la década de 1820 algunos sectores vinculados con Andrew Jackson se identificaron como "demócratas". Los "padres fundadores" norteamericanos miraron con recelo la democracia, cuando no la rechazaron explícitamente? Para Francia, Pierre Rosanvallon ha señalado un fenómeno análogo, pues la democracia fue una palabra desprestigiada, asociada íntimamente con la anarquía, que solo alcanzó amplia difusión y una valoración positiva recién hacia $1848,{ }^{10}$ un proceso similar al descrito por Javier Fernández Sebastián para el caso español ${ }^{11}$.

Solo teniendo en mente esta dimensión comparativa es posible ponderar la ambigua utilización del concepto de democracia en Chile en el período histórico

\footnotetext{
${ }^{6}$ Collier, David y Levitsky, Steven. "Democracy with Adjectives. Conceptual Innovation in Comparative Research", World Politics, 49 (1997): 430-451.

${ }^{7}$ Smith, Peter H. Democracy in Latin America: Political Change in Comparative Perspective. Oxford: Oxford University Press, 2005.

${ }^{8}$ Palmer, R. R. "Notes on the Use of the Word «Democracy» 1789-1799", Political Science Quarterly, 68/2 (1953): 203-226.

${ }^{9}$ Dupuis-Déri, Francis. "The Political Power of Words: The Birth of Pro-Democratic Discourse in the Nineteenth Century in the United States and France", Political Studies, 52 (2004): 118-134.

${ }^{10}$ Rosanvallon, Pierre. "The History of the Word «Democracy» in France", Journal of Democracy, 6/4 (1995): 140-154.

${ }^{11}$ Fernández Sebastián, Javier. "Democracia”. Diccionario politico y social del siglo XIX español. En Javier Fernández Sebastián y Juan Francisco Fuentes (dirs.). Madrid: Alianza, 2002, 216-221.
} 
aquí examinado. En el caso de la democracia, su polisemia resulta fundamental para comprender aquellos sentidos del concepto que causaban mayor rechazo. Particularmente, porque como ha notado Adam Przeworski, este concepto ha tenido significados diversos y cambiantes en el tiempo, en función de su problemática conexión con algunos de los grandes problemas políticos con los cuales se le ha vinculado: su relación con la igualdad, su filiación con la idea de participación, y su asociación con un diseño institucional que permita el goce de ciertos derechos que permitan caracterizar a un régimen como "democrático"12. Estas múltiples asociaciones con otros conceptos políticos fundamentales que caracteriza a la democracia -y subrayarían su condición aporética-, nos obligan a precisar aquellas dimensiones de la misma que provocaban menos resistencia a los actores de la época.

El propósito de este trabajo es analizar en detalle los usos y articulaciones del concepto de democracia durante el período independentista chileno, entre 1808 y 1833. El momento escogido es particularmente relevante en la trayectoria del concepto en el debate político nacional, en tanto contiene sus primeras exposiciones, defensas y rechazos en la discusión pública, todo esto en un contexto de cambio histórico de proporciones inéditas y de polarización política. La intención de este artículo es doble: por una parte, busca aumentar el acervo historiográfico sobre estos tópicos -en el que ya existen aportes, aunque breves $-{ }^{13}$, contribuyendo así a una veta de trabajo que recién ha comenzado a examinarse en el campo nacional. En segundo lugar, pretende cuestionar dos típicas aproximaciones al problema. Por un lado, de aquella historiografía que homologa la democracia a la historia del liberalismo, en una visión teleológica que narra el ascenso del paradigma democrático contra las dificultades que le impondría la sociedad tradicional, en un registro cercano a la visión $w$ hig de la historia ${ }^{14}$. Por otra, critica a la historiografía que le reprocha a los actores del período no ser lo suficientemente democráticos, utilizando una noción excesivamente normativa y ahistórica del concepto, otorgándole además validez retrospectiva. El proceso independentista, en el registro de León, por ejemplo, solo fue "la más fea y horrible de las revoluciones burguesas", cuya única finalidad fue la "proletarización" del bajo pueblo ${ }^{15}$.

\footnotetext{
${ }^{12}$ Przeworski, Adam. Democracy and the Limits of Self-Government. Cambridge: Cambridge University Press, 2010.

${ }^{13}$ San Francisco, Alejandro. "Democracia-Chile". Diccionario politico y social del mundo iberoamericano, t. II, v. 2. Javier Fernández Sebastián (dir.). Madrid: Centro de Estudios Políticos y Constitucionales/ Universidad del País Vasco (2014): 101-115.

${ }^{14}$ Amunátegui Solar, Domingo. La democracia en Chile/Teatro politico (1810-1910). Santiago de Chile: Universidad de Chile, 1946.

${ }^{15}$ León, Leonardo. Ni patriotas ni realistas. El bajo pueblo durante la Independencia de Chile, 18101822. Santiago de Chile: DIBAM/Centro de Investigaciones Diego Barros Arana, (2012): 98 y 70.
} 
Para cumplir con estos propósitos, en una primera parte examino las iniciales articulaciones del concepto, en un tenor marcadamente expositivo, sus primeras enunciaciones en un registro positivo por los defensores del republicanismo, para finalizar con el discurso absolutista que homologó democracia a anarquía. En un segundo apartado analizo los usos de la democracia en las discusiones relativas a la institucionalización de la revolución en el período comprendido entre 1818 y 1833 , enfocándome en las polémicas relativas al vínculo entre democracia, participación, igualdad política y gobernabilidad.

\section{EL CONCEPTO DE DEMOCRACIA EN LA INDEPENDENCIA CHILENA}

Las primeras referencias al concepto de democracia en el debate público chileno del período independentista remitían a la distinción clásica entre las formas de gobierno, de allí que sus usos respondiesen a fines más bien descriptivos antes que polémicos. Ese fue, por ejemplo, el tenor de la disertación universitaria en la que Manuel Gorbea y Badillo defendió, en 1808, "la preferencia del gobierno Monárquico al aristocrático y democrático" ${ }^{16}$. En ese mismo registro expositivo -aunque con una valoración distinta- fue presentado el concepto de democracia en el Catecismo político-cristiano, publicado bajo el pseudónimo de José Amor de la Patria a mediados de 1810. En una peregrina distinción de las formas de gobierno, en tanto no remitía a ninguna de las divisiones de la teoría política clásica, el autor diferenciaba tres tipos de gobierno: el monárquico, el despótico y el republicano, incluyendo a la democracia como una ramificación de este último. Lo que distinguía a la variante democrática de la aristocrática del republicanismo, era que en la primera "manda todo el pueblo por sí o por medio de sus representantes o diputados". Lo sugerente era la valoración que se hacía de la democracia. A diferencia de lo defendido por Gorbea y Badillo, en el Catecismo el republicanismo en su variante democrática era la mejor forma de gobierno, la única donde se "conserva la dignidad y majestad del pueblo [...] el más moderado, el más libre y es, por consiguiente, el mejor para hacer felices a los vivientes racionales"17.

Camilo Henríquez, por su parte, también contribuyó a presentar el concepto de democracia en clave expositiva, a propósito de la división de las formas

\footnotetext{
${ }^{16}$ La disertación de Gorbea y Badillo se infiere de la glosa realizada por Bernardo de Vera y Pintado, en "Rasgo de don Manuel de Gorbea y Badillo, en la función pública en que sostuvo la preferencia del gobierno monárquico al aristocrático y democrático, dedicando su aserto a Fernando VII", en Colección de Historiadores y Documentos relativos a la Independencia de Chile. Santiago de Chile: 1900-1966, t. XXX, 273.

${ }^{17}$ Amor de la Patria, José. Catecismo politico-cristiano. Buenos Aires: Francisco de Aguirre, 1969, 6-9.
} 
de gobierno. Inscrito en un registro cercano a Polibio ${ }^{18}$, el editor de la Aurora de Chile insistió en la división clásica de los regímenes -monarquía, aristocracia, democracia- pero también enfatizó la variación histórica de los mismos, fruto de su degeneración -la democracia que se desliza hacia la "anarquía”, la monarquía a la "arbitrariedad" y la aristocracia, definida como "el más inmoral de los gobiernos". Lo relevante de la exposición de Henríquez fue exhibir la idea del "gobierno mixto" como el mecanismo institucional que permitiría morigerar "los defectos y males de los gobiernos simples", presentando como ejemplos a EE.UU. y, especialmente, a la monarquía británica ${ }^{19}$.

Fue solo cuando el escenario político se deslizó desde el fidelismo al autonomismo, y tras 1813 -con la guerra de por medio- hacia una defensa abierta del autogobierno, que el concepto de democracia comenzó a utilizarse en registros semánticos distintos a la clásica diferenciación de regímenes políticos. Sintomáticamente, las primeras defensas públicas del republicanismo enfatizaron el contenido igualitario asociado a su semántica, una connotación que los contemporáneos atribuían a la democracia. En otros términos, era justamente la dimensión de igualdad política contenida en la democracia uno de los rasgos más valorables para los publicistas del republicanismo, como Camilo Henríquez o Bernardo de Vera y Pintado. En una diatriba contra la aristocracia, el fraile de la Buena Muerte se refirió a las negativas consecuencias de la "perjudicial desigualdad", porque "ella hace a la clase más numerosa y útil y que forma los ejércitos, insensible a los intereses y peligros de la patria", concluyendo: "Mala política tiene el que no demuestra ideas populares y democráticas en las circunstancias en que necesita de todos" 20 . Esta positiva conceptualización de la democracia asociada a la igualdad política no fue aislada. En una epístola pública dirigida por Bernardo de Vera y Pintado a Henríquez, el abogado santafesino elogió la naciente república paraguaya por la amplia participación ciudadana en los asuntos públicos, constituyendo "una especie de democracia que universaliza el influjo en los negocios públicos hasta el último ciudadano". Con un régimen de ese tipo, agregaba, no solo "irá desvaneciéndose progresivamente aquel hábito infeliz de respeto del pueblo llano a los aristócratas", sino que haría de cada hombre un ciudadano que "tomará interés por el bien de su patria porque ha comprendido tenerlo en el de sí mismo y de su familia" ${ }^{21}$.

\footnotetext{
${ }^{18}$ Bobbio, Norberto. La teoría de las formas de gobierno en la historia del pensamiento político. México D.F.: Fondo de Cultura Económica, (1987): 44-54.

${ }^{19}$ Henríquez, Camilo. "De las diversas formas de gobierno. De los gobiernos simples y regulares", Aurora de Chile, 28 de mayo de 1812.

${ }^{20}$ Henríquez, Camilo. "Carta al redactor por Roque Harizmenlic", El Monitor Araucano, 17 de diciembre de 1813.

${ }^{21}$ De Vera y Pintado, Bernardo. "Artículo comunicado", El Semanario Republicano, 11 de diciembre de 1813.
} 
La derrota de las tropas revolucionarias a mediados de 1814 y el restablecimiento de la monarquía absoluta en la metrópoli tuvo repercusiones decisivas en la semántica de la democracia. El elemento clave de este proceso sería su asociación con el desorden y la anarquía, justamente aquellos factores que habrían sintetizado la experiencia revolucionaria en el diagnóstico de los publicistas de la monarquía. Fray José María de la Torre, editor del periódico Viva el Rey, contrastó la situación del continente antes y después de la revolución: "América obediente, sumisa, leal a sus monarcas prosperó por espacio de tres siglos", mientras que "pocos ańos de malhadada democracia han bastado para despojarla de su dicha" 22 . Por cierto, el discurso del monarquismo chileno se hacía eco del panorama global tras el Congreso de Viena. En el caso peninsular la revalorización de la monarquía absoluta quedó en evidencia en el "Manifiesto de los persas". La monarquía absoluta, apuntaba el documento, "es una obra de la razón y de la inteligencia: está subordinada a la ley divina, a la justicia y a las reglas fundamentales del estado". Esto permitía a sus súbditos gozar de la misma libertad que en una república, pero sin estar sujetos a la inestabilidad y a la tiranía popular de esta última forma de gobierno, en especial cuando se relacionaba con la democracia ${ }^{23}$. El mismo Fernando VII delineó el discurso que sería hegemónico en esos años en su Manifiesto de Valencia, cuando declamó contra el espíritu revolucionario, prometiendo que "las ideas democráticas y los principios republicanos, han de quedar sepultados para siempre, bajo las ruinas y sangre que han ocasionado" 24 .

Lo significativo de ese momento es que el fracaso de la primera etapa revolucionaria, significó también la sospecha creciente hacia la democracia en los propios círculos que habían liderado el proyecto independentista. El caso más sintomático es el de Camilo Henríquez, quien en su Ensayo acerca de las causas de los sucesos desastrosos de Chile, evaluó cómo el faccionalismo y la falta de virtud cívica, entre otros factores, había precipitado el fracaso revolucionario, llegando a afirmar que "es locura querer establecer repúblicas donde se hable la lengua española"25. El decrecimiento del optimismo republicano inicial del clérigo y su alejamiento del paradigma democrático, se acentuaron en el exilio bonaerense, situación que explica la traducción, en 1816, de la obra de Robert Bisset Bosquejo de la democracia, escrita bajo los efectos de la Revolución Francesa, en 1796. La traducción, que Henríquez dedicó a los congresistas rioplatenses para que considerasen "los

\footnotetext{
${ }^{22}$ De la Torre, José María, “Continuación del artículo suspenso en el número 15”, Viva el Rey, 06 de febrero de 1816.

${ }^{23}$ Representación y manifiesto que algunos diputados a las Cortes ordinarias firmaron en los mayores apuros de su opresión en Madrid. Madrid: Imprenta de Ibarra, (1814): 53-54.

24 "Manifiesto del Sr. D. Fernando VII", Viva el Rey, 22 de diciembre de 1814.

${ }^{25}$ Henríquez, Camilo. "Ensayo acerca de las causas de los sucesos desastrosos de Chile". Raúl Silva Castro (comp.) Escritos políticos de Camilo Henríquez. Santiago: Universidad de Chile, 1960, 188.
} 
luminosos principios y las observaciones útiles y profundas, contenidas en esta pequeña obra" ${ }^{26}$, buscaba mostrar históricamente los yerros a los que había dado lugar el modelo democrático en la antigüedad y, desde allí, extraer principios que desaconsejaran su implementación en las naciones modernas. Como sostenía Bisset: "Sería fácil mostrar por la historia moderna que la democracia ha sido en todos tiempos subversiva del orden social, y destructora de la felicidad pública" ${ }^{27}$.

\section{ADHESIONES Y RECHAZOS EN UN PERÍODO DE FUNDACIÓN INSTITUCIONAL: 1818-1833}

Las victorias en las batallas de Chacabuco (1817) y Maipú (1818) permitieron el control del Valle Central por parte de las tropas revolucionarias, facilitando un contexto propicio para la formalización del autogobierno -cuyo rasgo más patente fue la declaración de Independencia a inicios de 1818- pero también, inaugurando la transición desde el momento bélico al momento constitucional, es decir, el paso desde la lucha por la libertad política hacia una institucionalización de la misma. En ese contexto intelectual que atravesó la discusión de toda la década de 1820, el concepto de democracia tuvo una presencia mucho más consistente-y también más polémica- en el debate público.

Tal vez la ambigüedad en sus usos sea uno de los rasgos distintivos en aquel momento. En efecto, la experiencia revolucionaria previa había proporcionado una panoplia relativamente conocida de asociaciones semánticas y valoraciones del concepto que se prosiguieron en la década transcurrida desde la declaración de Independencia. En un registro positivo, por ejemplo, los usos de la democracia como término opuesto a la aristocracia recogieron parte de la discusión previa. Las reflexiones sobre esta perspectiva remitían a una dimensión marcadamente sociológica de la democracia, que expresaba una forma especial de relacionarse entre los individuos, caracterizada por la igualdad. Esto fue lo que sostuvo El Liberal al criticar la estratificación social chilena, caracterizada por unas pocas familias ricas "a quienes el pueblo numeroso, abatido y miserable está acostumbrado a mirar con cierta especie de culto", fenómeno que era "bien distinto del espíritu democrático"28. En la misma línea estuvieron las reflexiones de Santiago Muñoz Bezanilla y José Santiago Luco al elaborar un proyecto sobre las milicias provinciales en 1825. Según aseguraban, "la distancia en que ha vivido el rico del pobre, el propietario de su

\footnotetext{
${ }^{26}$ Henríquez, Camilo, prólogo a Robert Bisset, Bosquejo de la democracia. Buenos Aires: Imprenta de M. J. Gandarillas, 1816, t. I, s.p.

${ }^{27}$ Bisset, Bosquejo de la democracia, t. II, p. 44.

28 "Carta al Sr. D. Juan Egańa”, El Liberal, 15 de enero de 1825.
} 
inquilino, el comerciante de su dependiente, etc., ha hecho ejercitarse un despotismo sin límites, y sostener una superioridad enorme en todos los actos de la vida”. Por esto, la organización de las milicias solo podría realizarse de acuerdo a estándares igualitarios "conforme vayan progresando la democracia y las virtudes cívicas"29.

Donde los usos polémicos de la democracia fueron más patentes fue en lo relativo a los marcos de la participación política popular. Dichas aprensiones fueron acentuados toda vez que la invocación de la democracia ya no remitía solo a una confrontación teórica con el régimen monárquico (como lo había sido en la década de 1810), sino más bien se relacionaban a la eventualidad de su implementación práctica en el nuevo régimen en construcción. En este escenario de prevención frente a la experimentación política y de morigeración del optimismo revolucionario nos ayuda a entender la breve pero significativa incursión de Bernardo de Monteagudo en la esfera pública chilena. Al igual que en el caso de Camilo Henríquez, la experiencia del exilio (en su caso europeo, entre 1815 y 1817) templaría su inicial optimismo revolucionario. Como confesaría unos años después el tucumano, el entusiasmo por la causa republicana que lo había caracterizado en los inicios del período revolucionario se debió "a las ideas demasiado inexactas que entonces tenía de la naturaleza de los gobiernos", hecho que lo había llevado a "abrazar con fanatismo el sistema democrático", hasta creer que "ser patriota sin ser frenético por la democracia era para mí una contradicción”. Las tareas periodísticas que asumió en Chile como redactor de El Censor de la Revolución, que él consignó como una forma de "expiar mis primeros errores", pues "ya estaba sano de esa especie de fiebre mental, que casi todos hemos padecido" ${ }^{30}$, clarifican el creciente recelo hacia el imperativo democrático que caracterizaría, en adelante, su trayectoria políticointelectual, particularmente en Perú ${ }^{31}$.

Por esto Monteagudo hizo hincapié, tras la declaración de Independencia chilena, en que el distintivo de la transición desde un régimen unipersonal a un gobierno representativo debía ser la moderación. Para esto era preciso maniobrar ante los excesos de los sistemas de gobierno "puros", estableciendo "una constitución moderadamente liberal" que permitiera efectuar dicha transición sin excesos. "Conocemos por experiencia los males del despotismo y los peligros de la democracia: ya hemos salido del período en que podíamos soportar el poder absoluto, y bien a costa nuestra hemos aprendido a temer la tiranía del pueblo,

\footnotetext{
29 "Oficio de la Comisión encargada de formar el Plan para la Organización de la Milicia Provincial", Registro Oficial de la Suprema Junta Interior Gubernativa, N 5, 1825.

${ }^{30}$ Monteagudo, Bernardo de. Memoria sobre los principios políticos que segui en la administración del Perú, y acontecimientos posteriores a mi separación. Santiago: Imprenta Nacional, 1823, 8.

${ }^{31}$ Montoya, Gustavo. La independencia del Perú y el fantasma de la revolución. Lima: IEP/ IFEA, 2002, 152-188.
} 
cuando llega a infatuarse con los delirios democráticos”, afirmaba ${ }^{32}$.

Este panorama intelectual permite contextualizar la muy conocida reflexión que a José M. Cea hizo Diego Portales en 1822. Portales, por entonces avecindado en Lima, comentaba los dilemas postrevolucionarios del continente, en especial, respecto a la elección del régimen de gobierno para los nuevos estados independientes. En esta disyuntiva, confidenciaba: "La democracia que tanto pregonan los ilusos es un absurdo en los países como los americanos, llenos de vicios y donde los ciudadanos carecen de toda virtud, como es necesario para establecer una verdadera república". Conseguida la virtud cívica, añadía, entonces "venga el gobierno completamente liberal, libre y lleno de ideales, donde tengan parte todos los ciudadanos" 33 . La reflexión de Portales se inscribe así dentro de los resquemores iniciales que despertaba el concepto de democracia, en especial respecto a su operatividad en un momento de transición política y de volatilidad del orden social. La forma de morigerar las expectativas democráticas consistía, por una parte, en agenciar adecuadamente el tiempo de la política, pero también en construir un horizonte de espera que dotase de dinamismo y carácter proyectual al proceso, ambos aspectos de la temporalidad de la democracia que Javier Santiso ha destacado de forma sugerente ${ }^{34}$.

No solo la virtud cívica, aquel "resorte que mueve a los estados democráticos", como indicó El Cosmopolita ${ }^{35}$, era entendida como uno de los requisitos para que esta forma de gobierno fuese una alternativa viable. También fue un tópico común la noción de que institucionalmente debían desplegarse mecanismos que aquilatasen el contenido popular asociado a la democracia. En este punto, resultó central la articulación del sintagma "democracia representativa", de origen norteamericano ${ }^{36}$, que vino a reformular lo que anteriormente había sido visto como una oppositio in terminis entre ambos conceptos ${ }^{37}$. Como ha explicado Gerardo Caetano a propósito de este problema, luego del recelo con que se miró al concepto de democracia tras la experiencia jacobina, fue su asociación con la idea de representación la que permitió "moderar" el contenido radical asociado a su semántica y permitir su uso cada vez más frecuente en el léxico político de la época ${ }^{38}$.

El principal introductor de esta fórmula en el debate público chileno

\footnotetext{
${ }^{32}$ El Censor de la Revolución, 20 de abril de 1820.

${ }_{33}$ Diego Portales a José M. Cea. Lima, marzo de 1822, en Carmen Fariña (ed.). Epistolario Diego Portales. Santiago de Chile: Ediciones Universidad Diego Portales, 2007, t. I, 8-9.

${ }^{34}$ Santiso, Javier. "À la recherche des temporalités de la démocratisation", Revue française de science politique, 44/6 (1994): 1079-1085.

35 "Consideraciones generales de política", El Cosmopolita, 18 de julio de 1822.

${ }^{36}$ Wood, Gordon S. "La democracia y la Revolución norteamericana”. Democracia: el viaje inacabado (508 a.C. - 1993 d.C.) John Dunn (dir.). Barcelona: Tusquets (1995): 111.

${ }^{37}$ Manin, Bernard. Los principios del gobierno representativo. Madrid: Alianza, (1998): 14.

${ }^{38}$ Caetano, Gerardo. "La reconceptualización política de la voz 'democracia' en Iberoamérica antes y después de las independencias", Crítica Contemporánea. Revista de Teoría Política, 1(2011): 101.
} 
fue Camilo Henríquez. Como hemos visto, tras el fracaso inicial del proyecto independentista el sacerdote se distanció del paradigma democrático. No obstante, a inicios de la década de 1820, una vez de regreso en el país, el descubrimiento por parte de Henríquez del modelo de la "democracia representativa" le permitió reflexionar desde una nueva óptica las formas bajo las cuales la democracia sí podía ser viable para el caso chileno. Como sugerentemente ha explicado Vasco Castillo, por medio de sus lecturas de los postrevolucionarios franceses como Constant, Daunou y, especialmente, de Desttut de Tracy, el sacerdote pudo erigirse como el principal articulador de la "solución representativa constitucional"39. Así, en una serie de artículos publicados en El Mercurio de Chile, Henríquez defendió la operatividad de ciertos principios democráticos, pero bajo la moderación del sistema representativo. En estos regímenes "el ejercicio de la soberanía no reside en la nación, sino en las personas a quienes la nación lo ha delegado". Esto resultaba fundamental, pues de no hacer esta distinción, entonces "habría dos verdaderos poderes en ejercicio, el de la masa total y el de sus representantes: en una palabra habría dos gobiernos, el uno democrático, y el otro representativo". El desconocimiento de estos principios, aclaraba el publicista, había llevado a los franceses a sus excesos durante el período jacobino. Solo por medio de la delegación de la soberanía originaria en los representantes se podía "moderar el ímpetu naturalmente democrático de las corporaciones populares"

Así, durante la década de 1820 el concepto de democracia fue utilizado con reparos, dependiendo tanto del contexto de enunciación como al aspecto que se deseara enfatizar dentro de su semántica. Como lo deja en evidencia el problema de la democracia representativa, fue un lugar común la idea de que la democracia, como forma de gobierno pura, tendía a la anarquía, o al "despotismo de la masa”, un tópico clave de la teoría política clásica. Había, entonces, que buscar un equilibrio político que, "proscribiendo la aristocracia bajo cualquiera forma, tampoco se abandone a una democracia salvaje", como sostuvo un periódico ${ }^{41}$. Juan Egaña aclaró que los desvaríos de la democracia se debían a una mala lectura histórica de la "igualdad republicana": "esto es que todo hombre libre y nacido en el país tiene igual voz y derecho para deliberar de la suerte del Estado". Tal tipo de lectura, llena de "errores falsos en teoría y funestísimos en la práctica" provocaba en general los "abusos de esta viciosa democracia". Ni siquiera en las "repúblicas griegas extremadamente democráticas", aclaraba Egańa, se había llegado a los

\footnotetext{
${ }^{39}$ Castillo, Vasco. La creación de la república. Santiago de Chile: LOM, 2009, 105-128.

${ }^{40}$ Henríquez, Camilo. “¿Qué es el pueblo en los gobiernos representativos?”, El Mercurio de Chile, 31 de agosto y 13 de septiembre de 1822 .

41 "Continúa el artículo opiniones sobre formas de gobierno", El Monitor Imparcial, 13 de septiembre de 1827.
} 
excesos de participación popular que algunos buscaban establecer en la actualidad. Los antiguos griegos "no entendían la democracia como ahora se pretende por algunos, y que acaso solo habrá existido entre los filbustiers [sic]" ${ }^{2}$.

En el debate constituyente de 1828, por ejemplo, el diputado Julián Navarro impugnó la implementación del modelo federalista absoluto, bajo el argumento de que ningún modelo político puro era indicado para sociedades complejas. La historia, señalaba, "ha manifestado que la monarquía absoluta es el patrimonio de un solo individuo; que todo lo reasume para sí, que la aristocracia es el patrimonio de los nobles, que desprecian al pobre y desgraciado, y que la democracia es el patrimonio de la multitud, que hace consistir su felicidad en el desorden y desarreglo de las cosas", concluía ${ }^{43}$. Un año después Juan Egaña remarcaría este punto, agregando que todos los gobiernos podían ser buenos "cuando hay costumbres que los respeten, y leyes que se ejecuten fielmente, a excepción del puramente democrático, que siempre es malo, aunque se compusiera el pueblo de Arístides y Phociones", pues llevaba a las sociedades a los "abusos del poder demagógico y popular" ${ }^{4}$.

Los recelos hacia la democracia pura y la aceptación del principio representativo, "sin el cual sería demasiado embarazoso por no decir imposible el gobierno democrático", según un periódico ${ }^{45}$, se vinculaban con la discusión en torno a los límites de la participación popular en las decisiones políticas, que algunos sectores consideraban como peligrosamente excesiva. En especial desde mediados de 1820, bajo el impulso del ideario federalista y la ampliación de espacios de participación política (como las asambleas provinciales y las elecciones), no fueron pocos quienes caracterizaron una estrecha relación entre federalismo y democracia, casi al punto de volverlos conceptos intercambiables. Así lo sostuvo la Asamblea Provincial de Colchagua en 1827, al decir que "el sistema federativo popular, que entendido en toda la extensión según la generalidad de la voz que sin modificación lo expresa, le induce al gobierno democrático" 46 .

La creciente valoración de ciertos sectores del liberalismo popular hacia algunos aspectos de la democracia representativa hizo que este fenómeno fuese cuestionable. Así, por ejemplo, el exiliado francés Pedro Chapuis criticó la excesiva

\footnotetext{
${ }^{42}$ Egaña, Juan, "Parte 2a de la memoria sobre federaciones y legislaturas", La Abeja Chilena, 21 de septiembre de 1825 .

${ }^{43}$ Congreso Constituyente, Sesión de 11 de marzo de 1828, en Valentín Letelier, Sesiones de los Cuerpos Lejislativos de la República de Chile, 1811 a 1845. Santiago de Chile: Imprenta Cervantes, 1887-1908, t. XV, 308. En adelante, citado como SCL.

${ }^{44}$ Juan Egaña, Ocios filosóficos y poéticos en la quinta de las delicias. Londres: Manuel Calero, 1829,

t. IV, 75-76.

45 "Sistema representativo", Miscelánea política y literaria, 20 de agosto de 1827.

${ }^{46}$ Oficio de la Asamblea Provincial de Colchagua, 17 de febrero de 1827, en SCL, t. XIV, 175.
} 
amplitud de la participación política a mediados de la década de 1820, fomentada por el "partido democrático". Para el redactor de El Verdadero Liberal el concepto de democracia, que equivalía a "soberanía del pueblo = gobierno popular = despotismo popular = subdivisión de la tiranía entre varios ciudadanos", terminaba significando "el gobierno de los locos", particularmente por la errada comprensión de la soberanía popular. Chapuis añadía: "Valiéndose a cada rato de las voces pueblo, soberanía del pueblo, los demócratas chilenos marchan a paso redoblado, sin saber a dónde van, pero sabiendo lo que quieren. Nunca podré persuadirme que un hombre de buena fe reconozca prácticamente la soberanía del pueblo, a no ser que esa soberanía sea ejercida por una parte electa de ese mismo pueblo". Y concluía: “¿A dónde iríamos a dar si las máximas de ese partido fueran adoptadas? Directamente a una revolución inevitable, al reinado del populacho" ${ }^{47}$.

A consideraciones similares llegó, meses después, Mariano Egaña desde Londres. En una confidencia a su padre, metaforizó el "furor democrático" con un "huracán" que estaba ocasionando estragos en Hispanoamérica.

Esta democracia, mi padre, es el mayor enemigo que tiene la América, y que por muchos años le ocasionará muchos desastres, hasta traerle su completa ruina. Las federaciones, las puebladas, las sediciones, la inquietud continua que no dejan alentar al comercio, a la industria y a la difusión de los conocimientos útiles: en fin tantos crímenes y tantos desatinos como se cometen desde Texas hasta Chiloé, todos son efectos de esta furia democrática que es el mayor azote de los pueblos sin experiencia y sin rectas nociones políticas ${ }^{48}$.

Como sabemos, los ensayos de apertura democrática de la década de 1820 fueron evaluados críticamente por el bando vencedor de la guerra civil iniciada en 1829. El cuestionamiento hacia lo que se entendió como una excesiva laxitud en la conceptualización de la ciudadanía política de aquellos años repercutió claramente en la problematización que hicieron sobre los marcos de participación política admisibles los sectores de una sensibilidad conservadora. El mismo voto fue resignificado, transitando desde su comprensión de este como un derecho al voto como una función pública. Y en tanto función pública, esta solo debía desempeñarse por los más aptos. El corolario de este proceso fue la eclosión de discurso capacitario en torno a la ciudadanía, expresados no solamente en los requisitos de alfabetización (una cuestión en todo caso transversal en la época) sino,

\footnotetext{
${ }^{47}$ Chapuis, Pedro, "De los partidos en Chile, o más bien en la capital", El Verdadero Liberal, 04 de enero de 1827 (cursivas en el original).

${ }^{48}$ Mariano Egaña a Juan Egańa, Londres, 21 de julio de 1827, Cartas de don Mariano Egaña a su padre 1824-1829. Santiago de Chile: Sociedad de Bibliófilos Chilenos, 1948, 262-263.
} 
sobre todo, en términos censitarios ${ }^{49}$. El nuevo énfasis en ambos elementos significó un proceso de "jibarización ciudadana”, como concluyen Pinto y Valdivia ${ }^{50}$.

El recelo hacia la democracia en su vínculo con la participación política remitía en especial al papel disruptor que se le asociaba tradicionalmente. Si la teoría política clásica y la experiencia revolucionaria acumulada insistían en que la democracia tendía a degenerar en anarquía, los constituyentes de 1833 terminaron parapetándose frente a dicho concepto, desplegando mecanismos institucionales que conjurasen el riesgo del desorden. La valoración del orden, un tema tan caro a la clase dirigente chilena ${ }^{51}$, se plasmó en aquellos años en el establecimiento de un marco constitucional autoritario que garantizasen la tranquilidad pública y la gobernabilidad, este último un elemento considerado frágil o inviable en un contexto democrático.

Así, no resulta extraño que en el balance crítico de la Constitución de 1828 que presentó en octubre de 1831 la comisión legislativa de la Gran Convención uno de los aspectos que evidenciaban la necesidad de reformarla eran las escasas atribuciones asignadas al Ejecutivo. Para defender este punto la comisión recurrió a la tesis del efecto perverso. Los constituyentes de 1828, guiados por "la exageración de la falsa democracia" habían potenciado al Poder Legislativo a expensas del Ejecutivo, creando así "una magistratura insignificante". Como a causa del prejuicio liberal contra la figura presidencial se habían puesto tantas trabas a su accionar, el liberalismo pipiolo había terminado consiguiendo un efecto perverso a sus propósitos originales: "por huir del despotismo de uno, se cae en el de todos o lo que es lo mismo, en la anarquía" 52 .

El fortalecimiento de la figura del Presidente en el diseño constitucional de 1833 se expresó de forma patente en el otorgamiento de facultades extraordinarias. Andrés Bello, en su comentario a la Constitución de 1833, explicó la necesidad de los poderes de emergencia en el nuevo diseño institucional. En la nueva carta, explicaba el caraqueño, el Presidente había "recibido el vigor necesario para obrar el bien, sometiendo a su autoridad todos los subalternos de que debe servirse para conservar el orden en todo el Estado". Los poderes de emergencia, a diferencia de los diseños constitucionales previos, le otorgaban "al poder fuerza para defenderse contra los ataques de la insubordinación, producida por los excesos de la democracia”,

\footnotetext{
${ }^{49} \mathrm{Cid}$, Gabriel. "Entre el miedo y la esperanza: democracia y ciudadanía en el debate público chileno, 1822-1851". Conflictos y tensiones en el Chile republicano. En Carlos Donoso y Pablo Rubio (eds.). Santiago de Chile: Universidad Nacional Andrés Bello/ RIL (2014): 91-93.

${ }^{50}$ Pinto, Julio y Valdivia, Verónica. ¿Chilenos todos? La construcción social de la nación (1810-1840). Santiago: LOM, 2009, 219.

${ }^{51}$ Stuven, Ana María. La seducción de un orden. Las elites y la construcción de Chile en las polémicas culturales y politicas del siglo XIX. Santiago de Chile: Ediciones Universidad Católica de Chile, 2000. ${ }^{52} S C L$, t. XXI, 11.
} 
aunque la institución del Consejo de Estado, afirmaba inmediatamente Bello -en una declaración inevitable dentro de un régimen constitucional- les otorgaría a los ciudadanos "recursos con que preservarse del despotismo" 53 .

\section{REFLEXIONES FINALES}

En el mundo contemporáneo, señala Alain Badiou, la democracia ha devenido en un "emblema", es decir, en un "elemento intocable de un sistema simbólico". La inmunidad frente a la crítica de los emblemas permite evaluar todo desde ese sitial -todo se puede criticar y juzgar en nombre de la democracia-, aunque a un costo altísimo: el de la reflexividad, ante las invocaciones más o menos espurias del concepto ${ }^{54}$. Me parece que un abordaje a la democracia desde la historia conceptual nos permite tomar distancia tanto de los esquemas presentistas como del prurito normativo de las ciencias sociales, devolviéndole al problema todo su espesor histórico y sus ambigüedades constitutivas. Frente a cierta historiografía, que le reprocha anacrónicamente a los actores del período aquí examinado no ser lo suficientemente democráticos ${ }^{55}$, un análisis como el aquí presentado nos permite reconstruir las ilusiones, rechazos y acomodos intelectuales de un momento de cambio histórico de dimensiones globales.

En efecto, este trabajo da cuenta de las diversas posiciones que los actores del período independentista plantearon frente a la democracia, visiones que deambularon desde su adhesión al rechazo abierto, con una amplia gama de opciones entre estos extremos, matices que remitían a distintas asociaciones semánticas de la democracia con otros conceptos políticos fundamentales, como la igualdad, la libertad o el pueblo.

En particular, las diversas valoraciones de la democracia remitían a un problema político de mayor envergadura, abierto justamente por la revolución independentista: el cómo organizar e institucionalizar el cambio histórico, y qué papel desempeńarían los sectores populares en este proceso. En ese sentido, la democracia quedó en la encrucijada de las ilusiones y temores desatadas por la revolución. Ilusiones, en la medida que las dirigencias intelectuales de la independencia entendían que el republicanismo había abierto un horizonte propicio para el desarrollo del autogobierno de los ciudadanos. Pero al mismo tiempo, la desestabilización económica y social provocada por el paso de la monarquía a república, y la siguiente etapa de

\footnotetext{
${ }^{53}$ El Araucano, 17 de mayo de 1833.

${ }^{54}$ Badiou, Alain. "El emblema democrático". Democracia en suspenso. Giorgio Agamben et. al., Madrid: Casus-Belli (2010): 17.

55 Por ejemplo, León, Ni patriotas ni realistas.
} 
esta transición, de la república a la democracia, pronto despertaron los temores de la misma clase dirigente. Esta tuvo que domesticar las expectativas revolucionarias y supeditar esta transición a un horizonte de acción futura, que permitía, eso sí, otorgarle dinamismo al proyecto republicano. Así, la democracia durante el período independentista tendió a quedar presa del temor al "reinado del populacho". Aunque el tiempo de la democracia quedó en suspenso, eso no significó su erradicación del léxico de la política. Fue una promesa aplazada que, hacia mediados del siglo XIX, para algunos actores exigía un cumplimiento urgente.

\section{REFERENCIAS}

Amor de la Patria, José. Catecismo politico-cristiano. Buenos Aires: Francisco de Aguirre, 1969.

Amunátegui Solar, Domingo. La democracia en Chile/Teatro politico (1810-1910). Santiago de Chile: Universidad de Chile, 1946.

Badiou, Alain. "El emblema democrático". Democracia en suspenso. Giorgio Agamben et. al., Madrid: Casus-Belli, 2010.

Bisset, Robert. Bosquejo de la democracia. Buenos Aires: Imprenta de M. J. Gandarillas, 1816.

Bobbio, Norberto. La teoría de las formas de gobierno en la historia del pensamiento político. México D.F.: Fondo de Cultura Económica, 1987.

Caetano, Gerardo. "La reconceptualización política de la voz 'democracia' en Iberoamérica antes y después de las independencias", Critica Contemporánea. Revista de Teoría Politica, 1, 2011.

Castillo, Vasco. La creación de la república. Santiago de Chile: LOM, 2009.

Cid, Gabriel. "Entre el miedo y la esperanza: democracia y ciudadanía en el debate público chileno, 1822-1851”. Conflictos y tensiones en el Chile republicano. En Carlos Donoso y Pablo Rubio (eds.). Santiago de Chile: Universidad Nacional Andrés Bello/ RIL, 2014.

Collier, David y Levitsky, Steven. "Democracy with Adjectives. Conceptual Innovation in Comparative Research”, World Politics, 49, 1997. 
Dahl, Robert A. A Preface to Democratic Theory. Chicago: The University of Chicago Press, 1956.

Dunn, John. Libertad para el pueblo. Historia de la democracia. México D.F.: Fondo de Cultura Económica, 2014.

Dupuis-Déri, Francis. "The Political Power of Words: The Birth of Pro-Democratic Discourse in the Nineteenth Century in the United States and France", Political Studies, 52, 2004.

Egaña, Juan. Ocios filosóficos y poéticos en la quinta de las delicias. Londres: Manuel Calero, 1829.

Egaña, Mariano. Cartas de don Mariano Egaña a su padre 1824-1829. Santiago de Chile: Sociedad de Bibliófilos Chilenos, 1948.

Fariña, Carmen. Epistolario Diego Portales. Santiago de Chile: Ediciones Universidad Diego Portales, 2007.

Fernández Sebastián, Javier. "Democracia”. Diccionario político y social del siglo XIX español. Javier Fernández Sebastián y Juan Francisco Fuentes (dirs.). Madrid: Alianza, 2002.

Hanson, Russell L. "Democracy". Political Innovation and Conceptual Change. En Terence Ball, James Farr y Russell L. Hanson (eds.). Cambridge: Cambridge University Press, 1989.

León, Leonardo. Ni patriotas ni realistas. El bajo pueblo durante la Independencia de Chile, 1810-1822. Santiago de Chile: DIBAM/Centro de Investigaciones Diego Barros Arana, 2012.

Letelier, Valentín. Sesiones de los Cuerpos Lejislativos de la República de Chile, 1811 a 1845. Santiago de Chile: Imprenta Cervantes, 1887-1908.

Manin, Bernard. Los principios del gobierno representativo. Madrid: Alianza, 1998.

Monteagudo, Bernardo de. Memoria sobre los principios politicos que segui en la administración del Perú, y acontecimientos posteriores a mi separación. Santiago de Chile: Imprenta Nacional, 1823. 
Montoya, Gustavo. La independencia del Perú y el fantasma de la revolución. Lima: IEP/ IFEA, 2002.

Palmer, R. R. "Notes on the Use of the Word «Democracy» 1789-1799", Political Science Quarterly, 68/2, 1953.

Pinto, Julio y Valdivia, Verónica. ¿Chilenos todos? La construcción social de la nación (1810-1840). Santiago de Chile: LOM, 2009.

Przeworski, Adam. Democracy and the Limits of Self-Government. Cambridge: Cambridge University Press, 2010.

Rosanvallon, Pierre. "The History of the Word «Democracy» in France”, Journal of Democracy, 6/4, 1995.

San Francisco, Alejandro. "Democracia-Chile". Diccionario politico y social del mundo iberoamericano, t. II, v. 2. Javier Fernández Sebastián (dir.). Madrid: Centro de Estudios Políticos y Constitucionales/ Universidad del País Vasco, 2014.

Santiso, Javier. "À la recherche des temporalités de la démocratisation", Revue française de science politique, 44/6, 1994.

Silva Castro, Raúl. Escritos politicos de Camilo Henriquez. Santiago de Chile: Universidad de Chile, 1960.

Smith, Peter H. Democracy in Latin America: Political Change in Comparative Perspective. Oxford: Oxford University Press, 2005.

Stuven, Ana María. La seducción de un orden. Las elites y la construcción de Chile en las polémicas culturales y politicas del siglo XIX. Santiago de Chile: Ediciones Universidad Católica de Chile, 2000.

Wood, Gordon S. "La democracia y la Revolución norteamericana". Democracia: el viaje inacabado (508 a.C. - 1993 d.C.). En John Dunn (dir.). Barcelona: Tusquets, 1995. 